\title{
INVESTIGATING THE EFFECT OF JOINT BEHAVIOR ON THE OPTIMUM DESIGN OF STEEL FRAMES VIA HUNTING SEARCH ALGORITHM
}

\author{
Erkan Doğan ${ }^{1}$, Soner Şeker ${ }^{2 *}$, M. Polat Saka ${ }^{3}$ and Celalettin Kozanoğlu ${ }^{1}$ \\ ${ }^{1}$ Celal Bayar University, Department of Civil Engineering , 45140, Manisa, Turkey \\ ${ }^{2}$ Uşak University, Department of Civil Engineering , 64200, Uşsak, Turkey \\ ${ }^{3}$ University of Bahrain, Department of Civil Engineering, Isa Town, Bahrain \\ *(Corresponding author: E-mail: soner.seker@usak.edu.tr)
}

Received: 21 April 2016; Revised: 13 April 2017; Accepted: 21 April 2017

\begin{abstract}
This study aims to carry out the effect of beam-to-column connections on the minimum weight design of steel plane frames. In the practical analysis of steel frames, end connections are assumed to be either fully restrained or pin-connected. However, experiments reveal that the real behavior is between these extremes and should be taken into account for the realistic design of structures. Hunting search algorithm is used for the automation of optimum design process. It is a numerical optimization method inspired by group hunting of animals such as wolves and lions. It is proven that it is a reliable and efficient technique for obtaining the solution of discrete structural optimization problems. Present design algorithm developed on the basis of hunting search algorithm selects $\mathrm{w}$ - sections for the members of semi rigid steel frame from the complete list of w- sections given in LRFD- AISC (Load and Resistance Factor Design, American Institute of Steel Construction). The design constraints are implemented from the specifications of the same code which covers serviceability and strength limitations. The selection of w-sections is carried out such that the design limitations are satisfied and the weight of semi- rigid frame is the minimum. In order to demonstrate its efficiency, three different steel frames are designed by the optimum design algorithm presented. The designs obtained by use of this algorithm are also compared with the ones produced by particle swarm optimization method.
\end{abstract}

Keywords: Stochastic Search techniques; hunting search algorithm; optimization problems; semi-rigid steel frames, end plate connections

DOI: $10.18057 /$ IJASC.2018.14.2.3

\section{INTRODUCTION}

In the analysis and design of steel frames, the realistic modeling of beam-to-column connections provides an accurate response of the frame under the external loads. In practice, these connections are assumed to be either fully rigid or perfectly pinned. In the former assumption, it is implied that there is no relative rotation of connection and the column takes the whole end moment of the beam. On the other hand, the pinned connection assumes that the moment of connection is always zero and there is no existing restraint for the rotation of connection. However, experiments have revealed that the real behavior of beam-to-column connections is between these extremes. Namely, all these practically used connections possess some stiffness falling between two cases mentioned above. Moreover, it is found that there exists a nonlinear relation of relative beam-to-column rotation when a moment is applied to a flexible connection [11]. These partially restrained connections influence the drift (P- $\Delta$ effect) of whole structure as well as the moment distribution in beams and columns. Use of a direct nonlinear inelastic analysis is one way to account for all these effects in frame design [1]. To be able to implement such analysis, beam-to-column connections should be assumed and modeled as semi-rigid connections. The semi-rigid connection flexibility depends on the geometric parameters of the elements used in beam-to-column connection, such as dimensions of end plates and bolt size. 
This study presents a hunting search method based optimum design algorithm for unbraced steel frames with semi rigid end connections. Hunting search algorithm is one of the recent additions to meta-heuristic search methods, which is inspired by group hunting of animals such as lions, wolves, and dolphins. Hunters involved in the hunting group encircle and catch their prey abiding by the certain strategies. For instance, wolves can hunt animals bigger or faster than themselves by relying on this kind of hunt. One prey is selected and the hunting group gradually moves toward it. The hunters avoid standing in the wind such that the prey senses their smell. This concept is used in the constrained problem to avoid prohibited regions. In the optimization process, each of the hunters indicates one solution for a particular problem. Similar to animals cooperate to find and catch the prey, the optimum design process seeks to find the optimum solution. Originally, hunting search algorithm produces continuous numbers. As made in some previously developed optimum design algorithms, this assumption can be used for the solution of many structural optimization problems [2]. However, such an assumption cannot be used in the optimum design problem of steel frames where the steel sections for its beams and columns are to be selected from a steel profile list, which consists of discrete values. Hence, discrete variables should be used in the hunting search algorithm. In literature, two approaches exist to obtain integer numbers from continuous ones. The first was suggested by Kennedy and Eberhart where binary numbers are used in the optimization algorithm to achieve a discrete set [16]. The second method is to round off the real numbers to the nearest integer numbers, which is suggested by Liu et al. [17]. In this study, discrete solution is accomplished by using rounding off technique due to its ease in the implementation of computer code.

Optimum design problem is formulated according to the specifications of LRFD-AISC [21]. The design constraints; displacement limitations, inter-storey drift restrictions of multi-storey frames, strength requirements for beam-columns are included in the formulation of the design problem. Furthermore, additional constraints namely geometric constraints are also considered to satisfy the practical requirements. The design problem formulated turns out to be a discrete nonlinear programming problem. The design algorithm developed selects $\mathrm{W}$ sections for beams and columns of an unbraced frame from discrete steel section list such that the design constraints imposed by LRFD-AISC are satisfied and the frame has the minimum weight.

\section{ANALYSIS OF UNBRACED STEEL FRAMES WITH SEMI-RIGID CONNECTIONS}

Various semi-rigid connection modeling and their moment-rotation relationships exist in the literature. The most well-known ones are linear, polynomial, cubic B spline, power and exponential models [12]. In the analysis and design of semi-rigid steel frames connections can be represented by discrete, inelastic rotational springs. The effect of connection flexibility is modeled by attaching rotational springs with stiffness moduli $\mathrm{K}_{\mathrm{A}}$ and $\mathrm{K}_{\mathrm{B}}$ to the first and second ends of a member as shown in Figure 1.
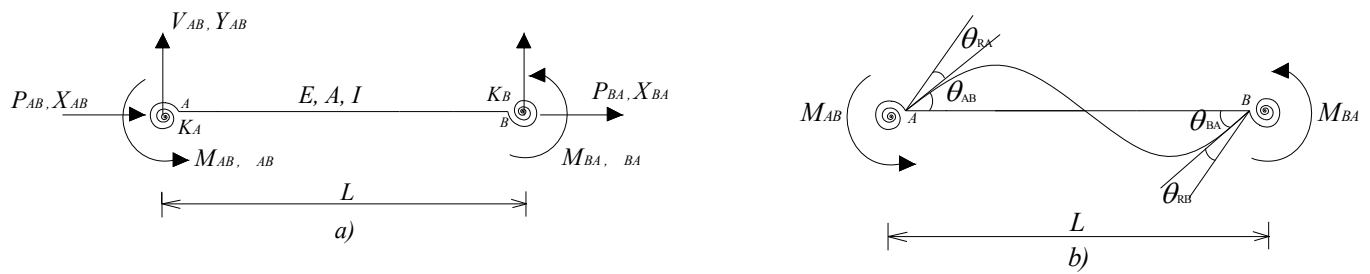

Figure 1. Semi-rigid Plane Beam Member with Rotational Springs
(a) End forces and end displacements
(b) end rotations 
A beam member with semi-rigid end connections has the nonlinear stiffness matrix form shown in the following. (Eq. 1)

Where;

$$
\begin{aligned}
& {[S T]=\left[\begin{array}{ccc|ccc}
A & & & & & \\
B & D & & & & \\
C 1 & E 1 & F 1 & & & \\
\hline-A & -B & -C 1 & A & & \\
-B & -D & -E 1 & B & D & \\
-C 2 & -E 2 & F 2 & C 2 & E 2 & G
\end{array}\right]} \\
& A=\frac{E A}{L}+\frac{12 E I}{L^{3}} f_{x 1} \phi_{5} \quad E_{1}=\frac{6 E I}{L^{2}} f_{x 2} \phi_{2} \\
& B=\frac{E A}{L}-\frac{12 E I}{L^{3}} f_{x 1} \phi_{5} \quad E_{2}=\frac{6 E I}{L^{2}} f_{x 3} \phi_{2} \\
& D=\frac{E A}{L}-\frac{12 E I}{L^{3}} f_{x 1} \phi_{5} \quad F_{1}=\frac{4 E I}{L} f_{x 6} \phi_{3} \\
& C_{1}=-\frac{6 E I}{L^{2}} f_{x 2} \phi_{2} \quad F_{2}=\frac{2 E I}{L} f_{x 5} \phi_{3} \\
& C_{2}=-\frac{6 E I}{L^{2}} f_{x 3} \phi_{2} \quad G=\frac{4 E I}{L} f_{x 6} \phi_{4}
\end{aligned}
$$

$$
\begin{array}{ll}
K K=K_{A} K_{B}+4\left(K_{A}+K_{B}\right)+12 & f_{x 4}=K_{A}\left(K_{B}+3\right) / K K \\
f_{x 1}=\left(K_{A} K_{B}+K_{A}+K_{B}\right) / K K & f_{x 5}=K_{A} K_{B} / K K \\
f_{x 2}=K_{A}\left(K_{B}+2\right) / K K & f_{x 6}=K_{B}\left(K_{A}+3\right) / K K \\
f_{x 3}=K_{B}\left(K_{A}+2\right) / K K &
\end{array}
$$

in which E represents the modulus of elasticity, L, I, A are the length, moment of inertia and area of beam, respectively. Above stiffness matrix includes the effect of the flexible connections. To be able to modify the stiffness matrix of a rigid beam, modification coefficients are used. These coefficients are calculated by use of the following equations.

In Eq. 2, $\mathrm{K}_{\mathrm{A}}$ and $\mathrm{K}_{\mathrm{B}}$ symbolize the stiffness moduli of the flexible connections at first and second end of the member. In addition, stability functions are included in the stiffness matrix to consider the effect of axial forces on the deformed shape. To calculate the values of stability functions, power series approximation is used. However, this method needs the trigonometric functions and one of which is $\alpha \cot \alpha$ gives singular values at some $\alpha$ values. For this reason, Livesely's approximation which is the sum of a power series in Euler critical load factor $\rho$ and a rotational function Eq. 3 is implemented [10]. These stability functions are given as follows;

$\phi_{1}=\alpha \cot \alpha=\frac{64-60 \rho+5 \rho^{2}}{(16-\rho)(4-\rho)}-\sum_{n=1}^{7} \frac{a_{n} \rho^{n}}{2^{3 n}}$

in which, the constants take the values as;

$$
\begin{array}{rrr}
\mathrm{a}_{1}=1.57973627, & \mathrm{a}_{2}=0.15858587, & \mathrm{a}_{3}=0.02748899, \quad \mathrm{a}_{4}=0.00547540, \\
\mathrm{a}_{5}=0.00115281, & \mathrm{a}_{6}=0.00024908, & \mathrm{a}_{7}=0.00005452 \\
\phi_{2}=\alpha^{2} /\left(3-3 \phi_{1}\right) & \alpha=0.5 \pi \sqrt{\rho} & \rho=\mathrm{P} / \mathrm{P}_{\mathrm{cr}}=\mathrm{Pl}^{2} /\left(\pi^{2} \mathrm{EI}\right) \\
\phi_{3}=\left(3 \phi_{2}+\phi_{1}\right) / 4 & & \\
\phi_{4}=\left(3 \phi_{2}-\phi_{1}\right) / 2 & \\
\phi_{5}=\phi_{2} \phi_{1} & &
\end{array}
$$

Where; $\mathrm{P}$ is the axial force in beam member, $\mathrm{P}_{\mathrm{cr}}$ is the Euler critical load of beam member. 


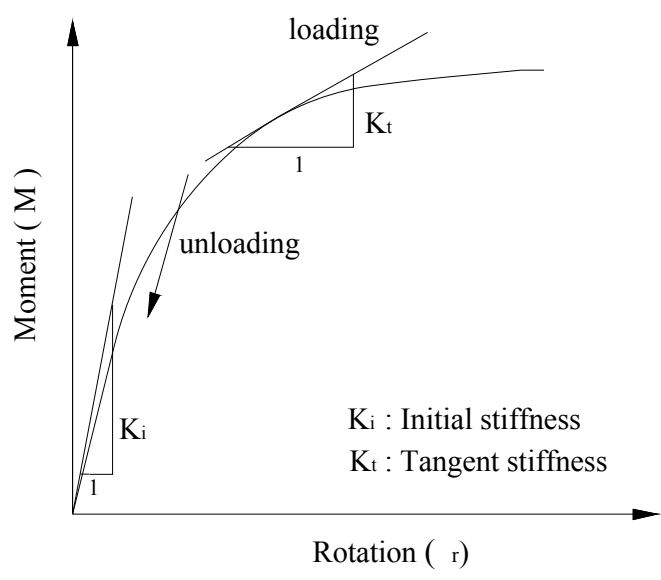

Figure 2. Moment Rotation Behavior of Semi-rigid Connection

In practice, curve-fitting the experimental data with simple expressions is the most commonly used approach to describe the $\mathrm{M}-\theta_{\mathrm{r}}$ curve of flexible connection. There are several analytical models to represent connection flexibility using available experimental test data. A polynomial model where $\mathrm{M}-\theta_{\mathrm{r}}$ behavior is represented by an odd power polynomial, proposed by Frye and Morris is adopted in present study due to its easy implementation [11]. The Frye and Morris model uses the method of least square to determine the constants of the polynomial and has the following form. (Eq. 5)

$\theta_{r}=C_{1}(K M)^{1}+C_{2}(K M)^{3}+C_{3}(K M)^{5}$

in which $\mathrm{C}_{1}, \mathrm{C}_{2}, \mathrm{C}_{3}$ are the curve-fitting constants and $K$ symbolizes the standardization constant dependent on the connection type and geometry. The values of these constants vary for each connection type and are given in the literature [13]. $\mathrm{K}_{\mathrm{A}}$ and $\mathrm{K}_{\mathrm{B}}$, called as the rotational stiffness of the springs at each end of the flexible frame member, are calculated as a tangent stiffness using above given nonlinear standardized function. (Eq. 5) To achieve this, first flexibility of connection is determined as $d \theta / d M$. Then, the stiffness of the connection, which is to be used in the modification of general stiffness matrix, is obtained as a reciprocal of the connection flexibility calculated for a certain value of a moment, when connection is loaded. If the state is unloading, the stiffness of the connection is assumed as its initial stiffness. These two states are shown in Figure 2. The size parameters of the end plate without column stiffeners connection, modeled in this study, are shown schematically in Figure 3. For the end plate without column stiffeners connection model, curve-fitting and standardization constants are given as in the following. (Eq. 6)

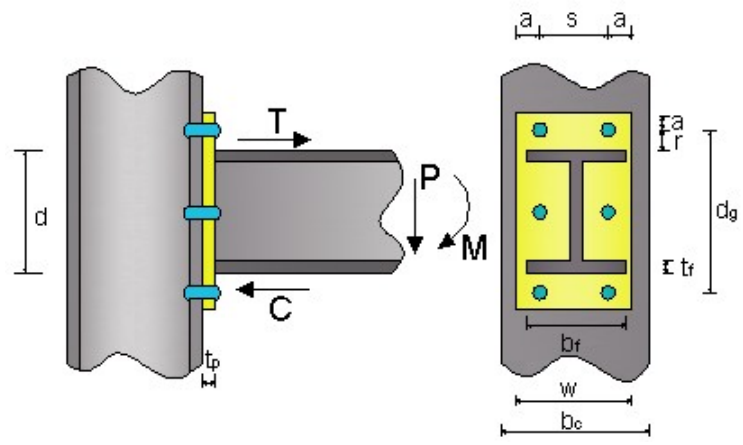

Figure 3. End Plate without Column Stiffeners Connection

$$
\mathrm{C}_{1}=1.83 \times 10^{-3} \quad \mathrm{C}_{2}=1.04 \times 10^{-4} \quad \mathrm{C}_{3}=6.38 \times 10^{-6} \quad \text { and } K=d_{g}^{-2.4} t_{p}{ }^{-0.4} d_{b}{ }^{1.5}
$$


where $d_{g}, t_{p}, d_{b}$ are; the distance between two bolts at the top and bottom of plate, the thickness of plate, and the diameter of bolts, respectively.

An increase in lateral displacements occurs in the analysis of steel frames with semi-rigid connections. Hence, consideration of the effect of axial forces in the response of semi-rigid frame becomes a necessity. The following steps give details about the algorithm, which accounts for $P-\Delta$ effect in the analysis of frame.

1. In the beginning of the procedure, axial forces in the frame members are assumed to be zero.

2. Overall stiffness matrix is constructed. Then the frame is analyzed under the external loads. Joint displacements and member forces are calculated.

3. Corresponding stability functions are determined using the axial forces obtained for the members.

The steps from 2 are repeated until the difference between two successive sets of axial forces is smaller than a specific tolerance.

The determinant of overall stiffness matrix is calculated and the loss of stability is checked during these iterations. If no loss of stability occurs and the convergence in the axial forces is obtained, the joint displacements and member forces determined in this nonlinear response are used in the computation of fitness values for this particle. During the analysis, the design load is applied immediately and the iterations are carried out at this load. It should be pointed out that the fixed end moments change in each iteration due to the rotational springs. The modified fixed end moments are determined by considering the flexible end connection.

\section{HUNTING SEARCH OPTIMIZATION FOR DISCRETE DESIGN VARIABLES}

The optimum design problem with discrete variables can be expressed as follows:

$\operatorname{Min} . f(x) \quad i=1, \ldots \ldots ., n$

Subject to;

$$
\begin{array}{ll}
g_{j}(x) \leq 0 & j=1, \ldots \ldots ., m \\
x_{i} \in X & , \quad X=\left\{x_{1}, x_{2}, \ldots \ldots x_{n}\right\}
\end{array}
$$

where $x_{i}$ represents the discrete design variable $i$, which is to be selected from the set $\boldsymbol{X}$ that contains $q$ number of discrete values for these variables. $n$ is the total number of design variables. $f\left(x_{i}\right)$ defines the objective function and $g_{j}\left(x_{i}\right)$ shows the design constraint $j . m$ is the total number of these constraints in the design problem.

Hunting search algorithm is one of the recent additions to the meta-heuristic search techniques of combinatorial optimization problems, introduced by Oftadeh et al [7]. This approach is based on the group hunting of animals such as lions, wolves and dolphins. The common part in the way of hunting of these animals is that, they all hunt in a group. They encircle the prey and gradually tighten the ring of siege until they catch the prey. Each member of the group corrects its position based on its own position and the position of other members during this action. If a prey escapes from the ring, hunters reorganize the group to siege the prey again. The hunting search algorithm is based on the way as wolves hunt. The procedure involves a number of hunters, which represents 
the hunting group are initialized randomly in the search space of an objective function. Each hunter represents a candidate solution of the optimum design problem. Originally hunting search algorithm produces continuous design variables. To be able to use the method for discrete design variables, some adjustments are required to be carried out. Firstly, the discrete values, among which the values of design variables $x_{i}$ are to be selected in set $\{\mathrm{X}\}$, are arranged in ascending sequence. The sequence number of these values is then treated as design variable instead of $x_{i}$ itself. For example in a design set, which consists of 272 values, the sequence numbers from 1 to 272 are the main design variables. At any stage of design cycle, once a sequence number is generated by the algorithm, then the real value of the design variable, which corresponds to this sequence number, is easily taken from the discrete set. The steps of the algorithm are given in the following:

1. Initialize the parameters: These are hunting group size (number of solution vectors in hunting group, $H G S$ ), maximum movement toward the leader $(M M L)$ and hunting group consideration rate $(H G C R)$, which varies between 0 and 1 . The parameters $M M L$ and $H G C R$ are used to improvise the hunter position (solution vector).

2. Initialize the hunting group: Based on the number of hunters $(H G S)$, the hunting group matrix is filled with feasible randomly generated solution vectors. The values of objective function are computed for each solution vector and the leader is defined depending on these values.

3. Generate new hunters' positions: New solution vectors $x^{\prime}=\left\{x_{1}^{\prime}, x_{2}^{\prime}, \ldots \ldots ., x_{n}^{\prime}\right\}$ are generated by moving toward the leader (the hunter that has the best position in the group) as follows;

$x_{i}=x_{t}+\operatorname{rans} \operatorname{MME}_{n}\left(x_{i}-x_{i}\right)$

where rand is a uniform random number $[0,1]$ and $x_{i}^{\prime}$ is the position value of the leader for the $i^{\text {th }}$ variable.

For each hunter, if the movement toward the leader is successful, the hunter stays in its new position. However, if the movement is not successful (its previous position is better than its new position) it comes back to the previous position. This provides two advantages. First, the hunter is not compared with the worst hunter in the group to allow the weak members to search for other solutions. They may find better solutions. Secondly, for prevention from rapid convergence of the group, the hunter compares its current position with its previous position; therefore, good positions will not be eliminated. The value of $M M L$ varies depending on the problem under consideration.

4. Position correction- cooperation between members: The cooperation among the hunters is required to be modeled in order to conduct the hunt more efficiently. After moving toward the leader, hunters (based on other hunter positions and some random factors) choose another position to find better solutions. Hunters correct their position either following "real value correction" or "digital value correction". In real value correction, the new hunter's position $x^{\prime}=\left\{x_{1}^{\prime}, x_{2}^{\prime}, \ldots \ldots ., x_{n}^{\prime}\right\}$ is generated from $H G$, based on hunting group considerations or position corrections. For instance, the value of the first design variable for the $j^{\text {th }}$ hunter $x_{i} j^{\prime}$ for the new vector, can be selected as a real number from the specified $H G\left(x_{i}^{1}, x_{i}^{2}, \ldots \ldots, x_{i}^{H G S}\right)$ or corrected using $H G C R$ parameter (chosen between 0 and 1). The variable is updated as follows:

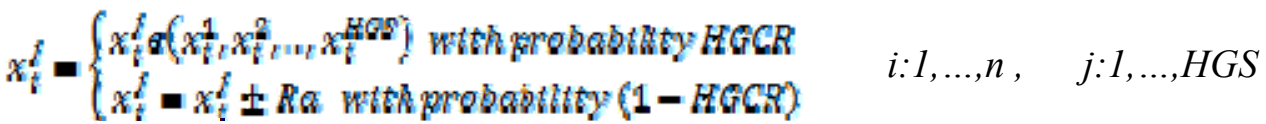

The parameter $H G C R$ is the probability of choosing one value from the hunting group stored in the $H G$. It is reported that selecting values between 0.1 and 0.4 produces better results. $R a$ is an arbitrary distance radius for the continuous design variable. It can be fixed or reduced during the optimization process. Several functions can be selected for reducing $R a$. Eq. 11 . 
$\mathrm{R} a(i t)=\mathrm{R} a_{\min }\left(x_{i}^{\max }-x_{i}^{\min }\right) \exp \left(\frac{\ln \left(\frac{R a_{\text {max }}}{R a_{\text {min }}}\right) \times i t}{i t m}\right)$

Where; it is the iteration number. $x_{i}^{\max }$ and $x_{i}^{\min }$ are the maximum and minimum possible values for $x_{i} . R a_{\max }$ and $R a_{\min }$ are the maximum and minimum of relative search radius of the hunter, respectively, and itm is the maximum number of iterations in the optimization process.

In digital value correction, instead of using real values of each variable, hunters communicate with each other by the digits of each solution variable. For example, the solution variable with the value of 23.4356 has six meaningful digits. For this solution variable, the hunter chooses a value for the first digit (i.e.2) based on hunting group considerations or position correction. After the quality of the new hunter position is determined by evaluating the objective function, the hunter moves to this new position; otherwise it keeps its previous position.

5. Reorganizing the hunting group: In order to prevent being trapped in a local optimum, they must reorganize themselves to get another opportunity to find the optimum point. The algorithm does this in two independent conditions. If the difference between the values of the objective function for the leader and the worst hunter in the group becomes smaller than a preset constant $\varepsilon 1$ and the termination criterion is not satisfied, then the algorithm reorganizes the hunting group for each hunter. Alternatively, after a certain number of searches, the hunters reorganize themselves. The reorganization is carried out as follows: the leader keeps its position and the other hunters randomly choose their position in the design space

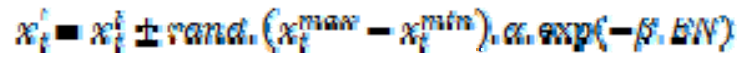

where $x_{i}^{1}$ is the position value of the leader for the $i^{\text {th }}$ variable. rand is a uniform random number between [0,1]. $\quad x_{i}^{\max }$ and $x_{i}^{\min }$ are the maximum and minimum possible values of variable $x_{i}$, respectively. $E N$ counts the number of times that the group has been trapped until this step. As the algorithm goes on, the solution gradually converges to the optimum point. Parameters $\alpha$ and $\beta$ are positive real values.

6. Termination: Steps 3-5 are repeated until maximum number of iterations is satisfied.

Constraint handling: In this study fly-back mechanism is used for handling the design constraints, which is proven to be effective in the literature [2]. Once all hunter positions $\mathrm{x}_{\mathrm{i}}$ are generated, the objective functions are evaluated for each of these and the constraints in the problem are then computed with these values to find out whether they violate the design constraints. If one or a number of the hunter gives infeasible solutions, these are discarded and new ones are re-generated. If some hunters are slightly infeasible, then such hunters are kept in the solution. These hunters, having one or more constraints slightly infeasible, are utilized in the design process that might provide a new hunter that may be feasible. This is achieved by using larger error values initially for the acceptability of the new design vectors and then reduce this value gradually during the design cycles and uses finally an error value of 0.001 or whatever necessary value that is required to be selected for the permissible error term towards the end of iterations. This adaptive error strategy is found quite effective in handling the design constraints in large design problems.

The pseudo code of the algorithm is given in Figure 4. 


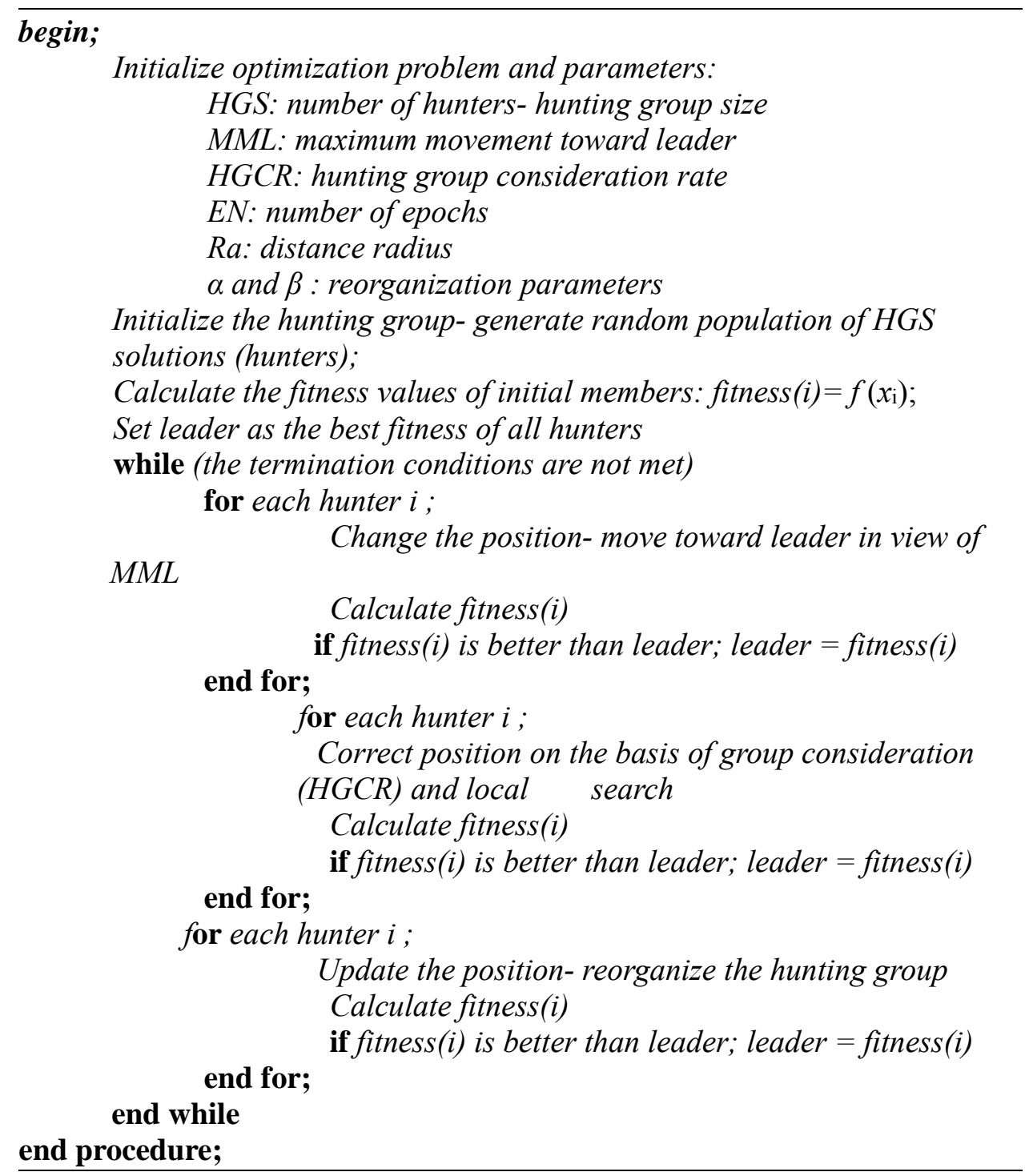

Figure 4. Pseudo Code for Hunting Search Algorithm

\section{DISCRETE OPTIMUM DESIGN OF UNBRACED STEEL FRAMES WITH SEMI-RIGID CONNECTIONS TO LRFD-AISC}

In the design of unbraced steel frames, the main concept is to select the readymade steel sections for its columns and beams from standard steel section tables. This design can be valid only if the serviceability and strength requirements specified by the code of practice are satisfied. In order to obtain an accurate response of the frame under the external loading, beam-to-column connections are assumed to be partially restrained. Hence, the stability analysis is included in the formulation of the design problem.

When the constraints are implemented from LRFD-AISC in the formulation of the design problem, the discrete optimum design problem of unbraced steel frames with semi-rigid beam-to-column connections, where the objective is the minimum weight can be expressed as follows:

Minimize;

$$
W=\sum_{k=1}^{n g} m_{k} \sum_{i=1}^{n k} L_{i}
$$


Subject to

$$
\begin{array}{ll}
\left(\delta_{\mathrm{j}}-\delta_{\mathrm{j}-1}\right) / \mathrm{h}_{\mathrm{j}} \leq \delta_{\mathrm{ju}} & \mathrm{j}=1, \ldots ., \mathrm{ns} \\
\delta_{\mathrm{i}} \leq \delta_{\mathrm{iu}} & \mathrm{i}=1, \ldots ., \mathrm{nd} \\
\mathrm{V}_{\mathrm{u}} \leq \phi \mathrm{V}_{\mathrm{n}} & \quad \text { for } \frac{P_{u}}{\phi_{c} P_{n}} \geq 0.2 \\
\left(\frac{P_{u}}{\phi_{c} P_{n}}\right)_{i l}+\left(\frac{8}{9}\left(\frac{M_{u x}}{\phi_{b} M_{n x}}\right)\right)_{i l} \leq 1.0 & \quad \text { for } \frac{P_{u}}{\phi_{c} P_{n}} \leq 0.2 \\
\left(\frac{P_{u}}{2 \phi_{c} P_{n}}\right)_{i l}+\left(\frac{M_{u x}}{\phi_{b} M_{n x}}\right)_{i l} \leq 1.0 & \mathrm{~s}=1, \ldots ., \mathrm{nu} \\
\mathrm{B}_{\mathrm{sb}} \leq \mathrm{B}_{\mathrm{sc}} \\
\mathrm{D}_{\mathrm{s}} \leq \mathrm{D}_{\mathrm{s}-1} \\
\mathrm{~m}_{\mathrm{s}} \leq \mathrm{m}_{\mathrm{s}-1}
\end{array}
$$

where Eq. 13 defines the weight of the frame, $n g$ is total numbers of groups in the structural system, $m_{k}$ is the unit weight of the steel section selected from the standard steel sections table that is to be adopted for group $k, L_{i}$ is the length of member $i$ that belongs to group $k, n_{k}$ is total number of members in group $k$. Eq. 14 represents the inter-storey drift of the multi-storey frame. $\delta_{j}$ and $\delta_{j-1}$ are lateral deflections of two adjacent storey levels and $h_{j}$ is the storey height. $n s$ is the total number of storeys in the frame. Eq. 15 defines the displacement restrictions that may be required to include other than drift constraints such as deflections in beams. nd is the total number of restricted displacements in the frame. $\delta_{j u}$ is the allowable lateral displacement. The horizontal deflection of columns is limited due to unfactored imposed load and wind loads to height of column / 300 in each storey of a building with more than one storey. $\delta_{i u}$ is the upper bound on the deflection of beams which is given as span/300 if they carry plaster or other brittle finish. Eq. 16 represents the shear capacity check for beam-columns. $\phi$ is resistance factor in shear, $V_{u}$ required shear strength, $V_{n}$ is nominal shear strength. Eq. 17 defines the local capacity check for beam-columns. $\mathrm{nm}$ is number of members, $n l$ is number of load cases, $M_{n x}$ is nominal flexural strength, $M_{u x}$ is applied moment, $P_{n}$ is nominal axial strength, $P_{u}$ is applied axial load, $\varnothing_{c}$ is resistance factor for columns if the axial force is in compression, $\varnothing_{b}$ is resistance factor in bending. It is apparent that computation of compressive strength $\phi_{c} P_{n}$ of a compression member requires its effective length. The computation of the effective length of a compression member in a frame can be automated by using Jackson and Moreland monograph [9]. Eq. 18 is included in the design problem to ensure that the flange width of the beam section at each beam-column connection of storey $s$ should be less than or equal to the flange width of column section. Eqs. 19-20 are required to be included to make sure that the depth and the mass per meter of column section at storey $s$ at each beam-column connection are less than or equal to width and mass of the column section at the lower storey $s-1$. $n u$ is the total number of these constraints Figure 5. 


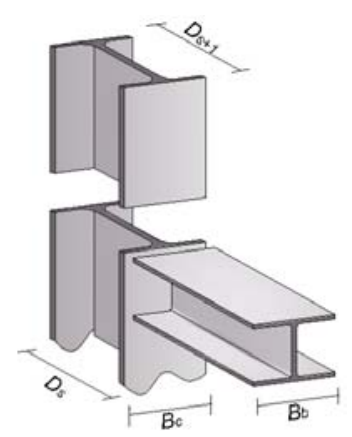

Figure 5. Geometry of Beam-column Connection

\subsection{Optimum Design Algorithm}

Solution of the discrete design problem given in Eqs. 13-20 is obtained using hunting search algorithm.

Hunting search method based optimum design algorithm treats the sequence number of the steel sections in the standard $\mathrm{W}$-section list as a design variable. Once a sequence number is selected, then the sectional designation and properties of that section becomes available for the algorithm. Therefore, the design vector consists of integer numbers that corresponds to the sequence numbers of $\mathrm{W}$-sections in the discrete set given in LRFD-AISC, which are selected for each group in the steel frame. The design algorithm consists of the following steps.

1. Select the values of parameters namely, hunting group size $H G S$, maximum movement towards leader $M M L$, hunting group consideration rate $H G C R$, maximum and minimum of relative search radius of the hunter $R a_{\max }$ and $R a_{\min }$, maximum iteration number itm, reorganization parameters $\alpha$ and $\beta$, number of epochs $E N$.

2. Generate hunter's positions. Select randomly sequence number of steel sections from the discrete list for each group in the frame.

3. Carry out the analysis of the steel frame with these sections, under the consideration of the stiffness matrix modified in such a way that the corresponding terms represent the flexibility of the beam-to-column connections. Check whether the design limitations are satisfied or not. If the hunter violates the design constraints severely, discard this hunter and repeat the selection of a new one. If it is slightly infeasible consider it for the hunting group.

4. Check whether the newly selected hunter is acceptable. If not, go to step 3.

5. After the selection of acceptable hunters, calculate the objective function value for each hunter. Determine the one which has the best objective function value.

\section{DESIGN EXAMPLES}

Three unbraced semi-rigid steel frames are designed using hunting search method based optimum design algorithm presented in the previous section. Effect of connection modeling on the minimum weight of frames is investigated. In addition, to demonstrate the efficiency of hunting search algorithm, the same examples are also solved with particle swarm optimizer which is proven to be robust and efficient in the solution of structural optimization problems. The discrete set, from which the design algorithm selects the sectional designations for frame members, is considered to be the complete set of $272 \mathrm{~W}$-sections starting from W100x19.3 to W1100x499mm as given in LRFD-AISC. For this study, hunting search algorithm parameters; $M M L, H G C R, R a_{\max }, R a_{\min }, \alpha, \beta$, 
$E N$ are chosen to be $0.005,0.3,0.01,0.001,1.2,0.02,25$, respectively. These values are decided after carrying out several trials in the design examples. Each example is solved with each method ten times with different seed values in order to inquire the effect of random numbers to optimum solutions. Algorithms perform this by producing different random number in each iteration by using call random_seed $(i)$, where $\mathrm{i}$ is the iteration number. Then the best one amongst them, which has the minimum frame weight, is accepted as the optimum design.

\subsection{Eight Storey- Six Bay Steel Frame}

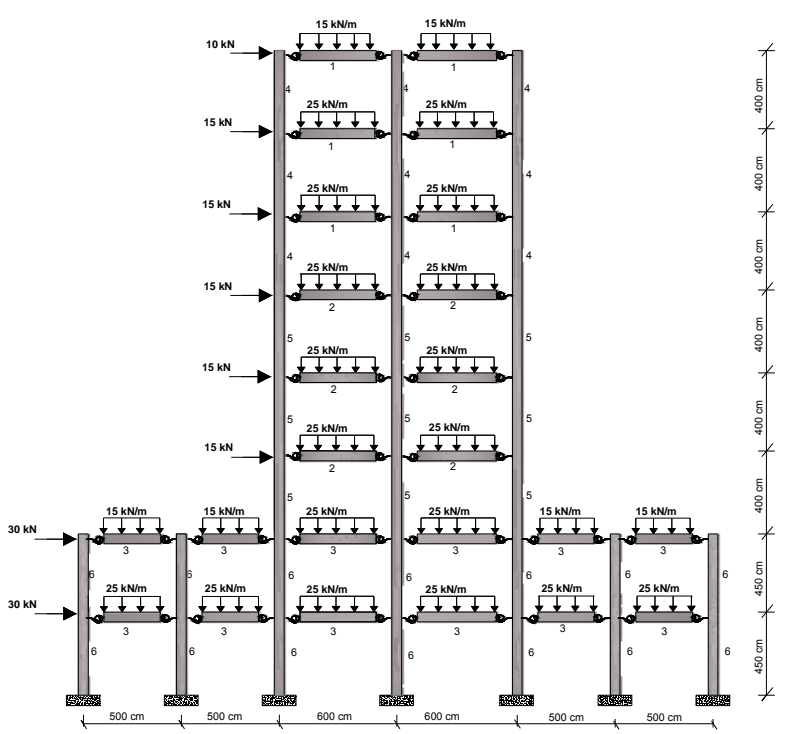

Figure 6. Eight-storey, Six-bay Steel Frame

The eight storey six bay steel frame shown in Figure 6 is considered as first design example. The frame consists of fifty six members that are collected in six groups as shown in Figure6. The allowable inter-storey drift is $1 / 300 \mathrm{~cm}$ of storey height while the lateral displacement of the top storey is limited to $1 / 300 \mathrm{~cm}$ of total height of the frame, which corresponds to $1.33 \mathrm{~cm}$ and $11 \mathrm{~cm}$, respectively. The modulus of elasticity is $200 \mathrm{kN} / \mathrm{mm}^{2}$.

At first, frame is designed ten times assuming the beam-to-column connections to be end plate without column stiffeners. Then, ten different designs are produced assuming the end connections to be fully restrained. Best, worst and average runs obtained by each method are given in Table 1 . The optimum W-sections designations obtained by the hunting search and particle swarm method are given in Table 2. Results obtained by the consideration of both end connection assumptions are tabulated.

Table 1. Minimum Weights (kg) obtained for Eight Storey Six Bay Frame

\begin{tabular}{|l|l|l|l|l|}
\cline { 2 - 5 } \multicolumn{1}{c|}{} & \multicolumn{2}{l|}{ PSO } & HuS & \multicolumn{1}{c|}{} \\
\cline { 2 - 5 } \multicolumn{1}{c|}{} & Rigid & Semi Rigid & Rigid & Semi Rigid \\
\hline Best Design (kg) & 13186,81 & 16313,780 & 13186,81 & 15423,360 \\
\hline $\begin{array}{l}\text { Average Design } \\
\text { (kg) }\end{array}$ & 15687,68 & 18220,35 & 14574,45 & 16281,440 \\
\hline Worst Design (kg) & 20293,76 & 29514,25 & 17561,62 & 17732,93 \\
\hline
\end{tabular}


Table 2. Optimum Designs for Eight-storey, Six-bay Steel Frame

\begin{tabular}{|l|l|l|l|l|l|}
\hline & & \multicolumn{2}{|l|}{ PSO } & HuS \\
\hline $\begin{array}{l}\text { Group } \\
\text { No }\end{array}$ & $\begin{array}{l}\text { Member } \\
\text { Type }\end{array}$ & Rigid & Semi Rigid & Rigid & Semi Rigid \\
\hline 1 & Beam & W410X46,1 & W410X38,8 & W410X46,1 & W410X38,8 \\
\hline 2 & Beam & W460X52 & W530X74 & W460X52 & W530X74 \\
\hline 3 & Beam & W460X52 & W530X66 & W460X52 & W460X52 \\
\hline 4 & Column & W250X32,7 & W310X38,7 & W250X32,7 & W410X38,8 \\
\hline 5 & Column & W310X52 & W410X67 & W310X52 & W410X67 \\
\hline 6 & Column & W460X52 & W410X67 & W460X52 & W410X67 \\
\hline $\begin{array}{l}\text { Maximum inter storey } \\
\text { drift ratio }\end{array}$ & 0,98 & 1,00 & 0,98 & 0,99 \\
\hline $\begin{array}{l}\text { Maximum } \\
\text { Ratio }\end{array}$ & Strength & 0,99 & 0,96 & 0,99 & 0,98 \\
\hline Top storey drift (cm) & 8,79 & 9,37 & 8,79 & 9,77 \\
\hline Minimum Weight (kg) & $\mathbf{1 3 1 8 6 , 8 1 0}$ & $\mathbf{1 6 3 1 3 , 7 8 0}$ & $\mathbf{1 3 1 8 6 , 8 1 0}$ & $\mathbf{1 5 4 2 3 , 3 6 0}$ \\
\hline
\end{tabular}

Convergence rate graphs of the optimum designs are shown Figure 7. The lightest design where the former assumption is made, weighs $13186.81 \mathrm{~kg}$. Hunting search algorithm and particle swarm optimizer produce the same design. However, it can be clearly seen from the figure that particle swarm optimizer shows better convergence in finding the optimum solution. On the other hand, it is noticed that the weight of the optimum design becomes $15423.36 \mathrm{~kg}$ in the case of latter assumption, which is obtained by hunting search algorithm. The one attained with particle swarm optimizer is $16313.78 \mathrm{~kg}$, which is $6 \%$ heavier than this design. This implies that the frames with semi-rigid end connections (end plate without column stiffeners) are heavier than the ones with rigid end connections.

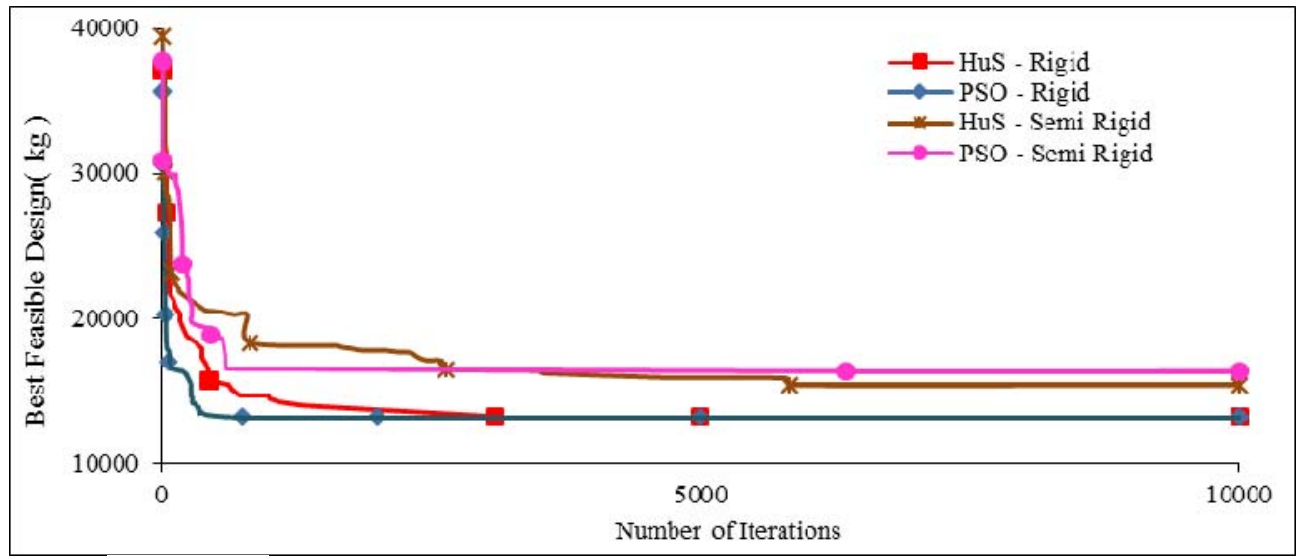

Figure 7. Design history graph for eight-storey, six -bay steel frame 


\subsection{Ten Storey Four Bay Steel Frame}

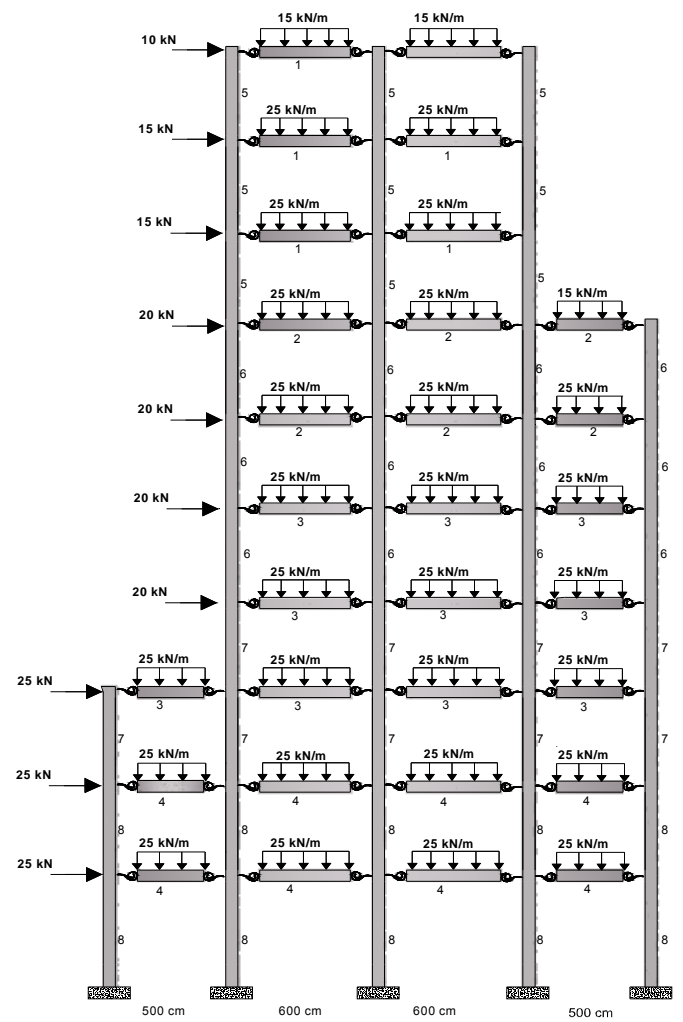

Figure 8. Ten-storey, Four-bay Steel Frame

Ten-storey, four-bay frame shown in Figure 8 is considered as second design example. The frame configuration dimensions, loading, joint numbering and member grouping are shown in the same figure. The frame consists of seventy members that are collected in eight groups as shown in the figure. Top storey drift is limited to $13.67 \mathrm{~cm}$, which is again $1 / 300 \mathrm{~cm}$ of total height of frame and inter-storey drift is restricted to $1.33 \mathrm{~cm}$ i.e. $1 / 300 \mathrm{~cm}$ of storey height of frame. The modulus of elasticity is $200 \mathrm{kN} / \mathrm{mm}^{2}$. Roof beams are loaded by uniform gravity loads of $15 \mathrm{kN} / \mathrm{m}$ while the others are loaded by those of $25 \mathrm{kN} / \mathrm{m}$. There are also lateral point loads acting on the joints at each story level. Material properties of steel profiles remain the same with the previous example.

This frame is also designed by use of both algorithms. Best, worst and average runs obtained by each method are given in Table 3. Optimum section designations for each design are given in Table 4. It is observed that maximum strength ratio of the optimum designs, obtained with hunting search and particle swarm methods, are 1.00 for rigid frames.

Table 3. Minimum Weights (kg) obtained for Ten-storey, Four-bay Steel Frame

\begin{tabular}{|l|l|l|l|l|}
\cline { 2 - 5 } \multicolumn{1}{c|}{} & \multicolumn{2}{l|}{ PSO } & HuS & \multicolumn{2}{c|}{} \\
\cline { 2 - 5 } \multicolumn{1}{c|}{} & Rigid & Semi Rigid & Rigid & Semi Rigid \\
\hline Best Design (kg) & 18121,55 & 22469,73 & 17663,79 & 21700,77 \\
\hline $\begin{array}{l}\text { Average Design } \\
\text { (kg) }\end{array}$ & 22282,53 & 28752,45 & 18311,73 & 23499,09 \\
\hline Worst Design (kg) & 35100,40 & 41649,03 & 23749,28 & 25472,10 \\
\hline
\end{tabular}


Table 4. Optimum Designs for Ten-storey, Four-bay Steel Frame

\begin{tabular}{|c|c|c|c|c|c|}
\hline & & \multicolumn{2}{|l|}{ PSO } & \multicolumn{2}{|l|}{ HuS } \\
\hline $\begin{array}{l}\text { Group } \\
\text { No }\end{array}$ & $\begin{array}{l}\text { Member } \\
\text { Type }\end{array}$ & Rigid & Semi Rigid & Rigid & Semi Rigid \\
\hline 1 & Beam & W410X46,1 & W410X38,8 & W410X46,1 & W360X44 \\
\hline 2 & Beam & W460X52 & W410X38,8 & W410X46,1 & W410X46,1 \\
\hline 3 & Beam & W460X52 & W460X60 & W460X52 & W530X66 \\
\hline 4 & Beam & W460X52 & W610X82 & W460X52 & W610X82 \\
\hline 5 & Column & W250X38,5 & W310X38,7 & W360X44 & W360X44 \\
\hline 6 & Column & W460X60 & W530X66 & W360X51 & W360X51 \\
\hline 7 & Column & W460X60 & W530X74 & W460X52 & W530X74 \\
\hline 8 & Column & W460X68 & W530X123 & W460X74 & W530X101 \\
\hline $\begin{array}{l}\text { Maximum } \\
\text { drift ratio }\end{array}$ & inter storey & 0,96 & 0,99 & 0,99 & 0,98 \\
\hline $\begin{array}{l}\text { Maximum } \\
\text { Ratio }\end{array}$ & Strength & 1,00 & 0,89 & 1,00 & 0,99 \\
\hline Top storey & $\operatorname{drift}(\mathbf{c m})$ & 10,39 & 10,65 & 10,81 & 10,36 \\
\hline Minimum & Neight (kg) & 18121,550 & 22469,730 & 17663,790 & 21700,770 \\
\hline
\end{tabular}

Besides, it is noticed that maximum inter-storey drift ratios are 0.99 and 0.96 for the same frames, respectively. This clearly indicates that the designs attained with fully restrained connection assumption are dominated by strength constraints. Hunting search produces rigid frame with the weight of $17663.79 \mathrm{~kg}$ and semi-rigid frame with the weight of $21700772 \mathrm{~kg}$, while the optimum designs of rigid and semi-rigid frames obtained with particle swarm weigh $18121.55 \mathrm{~kg}$ and $22469.73 \mathrm{~kg}$, respectively. This means that similar to first example, semi-rigid connection modeling gives heavier design for this frame configuration. Convergence rate graphs are shown in Figure 9.

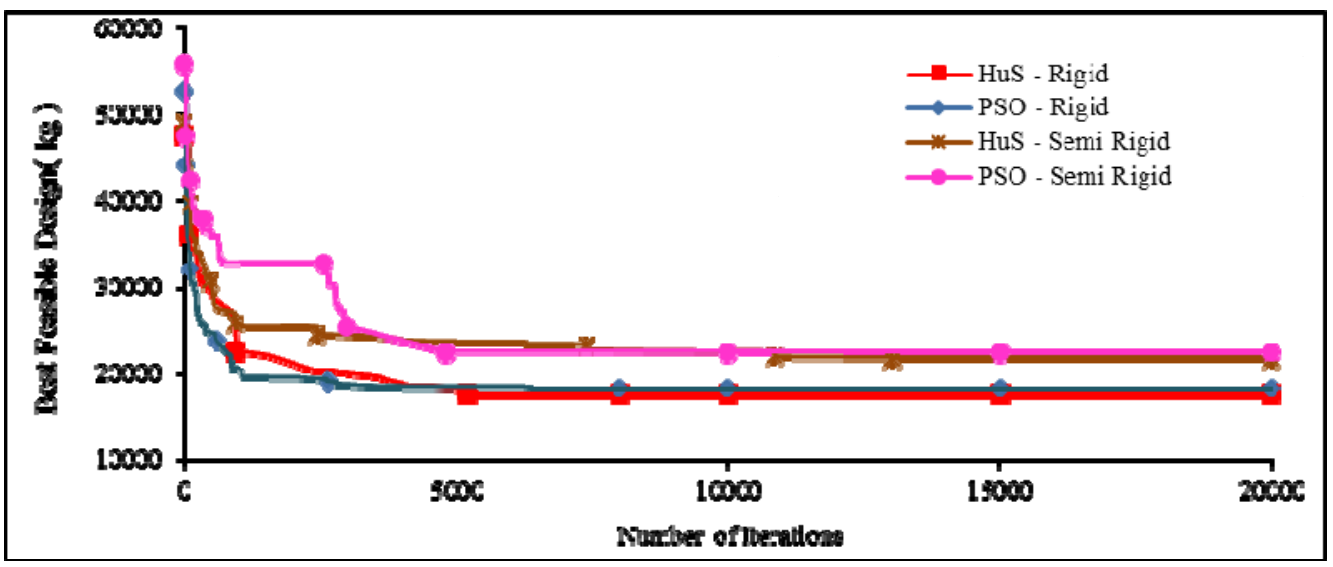

Figure 9. Design History Graph for Ten-storey, Four-bay Steel Frame

\subsection{Twelve Storey Four Bay Steel Frame}

Twelve-storey, four-bay frame shown in Figure 10 is considered to be the third design example. The same figure shows the frame configuration dimensions, loading, joint numbering and member grouping. Frame is composed of 108 members, 60 of which is column and 48 of which is beam. These frame members are collected in ten groups. Roof beams are loaded by uniform gravity loads of $15 \mathrm{kN} / \mathrm{m}$ while the others are loaded by those of $25 \mathrm{kN} / \mathrm{m}$. There are also lateral point loads acting on the joints at each story level. 
Frame is separately designed ten times using both methods. Best, worst and average runs are given in Table 5. Results reveal that hunting search technique attains lighter frame for both end connection assumptions. Optimum designs for rigidly connected frames achieved by HuS and PSO methods weight $39478,25 \mathrm{~kg}$ and $42220,05 \mathrm{~kg}$, respectively. On the other hand, semi rigid frames produced by the same methods weigh $61124,64 \mathrm{~kg}$ and $71699,77 \mathrm{~kg}$, respectively. These four designs are tabulated in Table 6 with section designations attained for each member group. This table also includes the maximum values of design constraints, reached in each design. According to these results, while the strength constraints dominate the rigid frames, inter-story drift constraints are effective in the solution of semi-rigid frames. Convergence rate graphs are given in Figure 11.

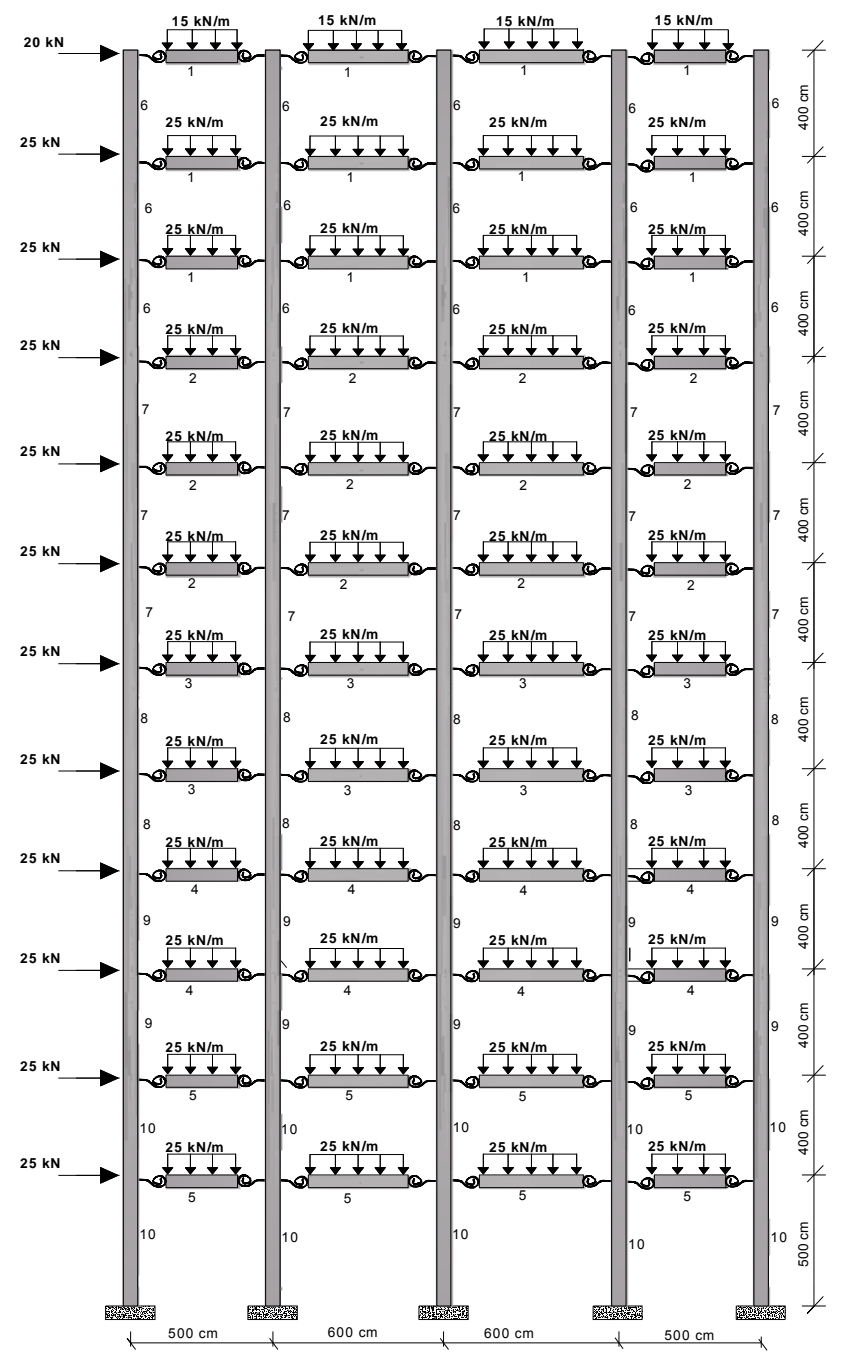

Figure 10. Twelve-storey, Four-bay Steel Frame

Table 5. Minimum Weights (kg) obtained for Twelve-storey, Four-bay Steel Frame

\begin{tabular}{|l|l|l|l|l|}
\cline { 2 - 5 } \multicolumn{1}{c|}{} & \multicolumn{2}{l|}{ PSO } & HuS & \multicolumn{1}{c|}{} \\
\cline { 2 - 5 } \multicolumn{1}{c|}{} & Rigid & Semi Rigid & Rigid & Semi Rigid \\
\hline Best Design (kg) & 42220,05 & 55089,580 & 39478,25 & 46451,310 \\
\hline $\begin{array}{l}\text { Average Design } \\
\text { (kg) }\end{array}$ & 53221,63 & 59680,44 & 47029,48 & 50605,04 \\
\hline Worst Design (kg) & 75877,34 & 79454,82 & 57512,21 & 59764,62 \\
\hline
\end{tabular}


Table 6. Optimum Designs for Twelve-storey, Four-bay Steel Frame

\begin{tabular}{|c|c|c|c|c|c|}
\hline \multirow[b]{2}{*}{$\begin{array}{l}\text { Group } \\
\text { No }\end{array}$} & \multirow[b]{2}{*}{$\begin{array}{l}\text { Member } \\
\text { Type }\end{array}$} & \multicolumn{2}{|l|}{$\mathrm{PSO}$} & \multicolumn{2}{|l|}{$\mathrm{HuS}$} \\
\hline & & Rigid & Semi Rigid & Rigid & Semi Rigid \\
\hline 1 & Beam & W410X46,1 & W360X60 & W410X46, 1 & W410X38,8 \\
\hline 2 & Beam & W460X60 & W530X66 & W410X67 & W460X52 \\
\hline 3 & Beam & W460X52 & W460X60 & W410X60 & W460X74 \\
\hline 4 & Beam & W460X60 & W530X74 & W460X68 & W460X52 \\
\hline 5 & Beam & W460X74 & W610X82 & W410X53 & W690X170 \\
\hline 6 & Column & W250X38,5 & W360X79 & W310X38,7 & W410X53 \\
\hline 7 & Column & W360X134 & W460X89 & W410X75 & W460X60 \\
\hline 8 & Column & W360X134 & W610X113 & W410X85 & W530X92 \\
\hline 9 & Column & W760X134 & W760X196 & W610X101 & W610X153 \\
\hline 10 & Column & W760X134 & W840X329 & W610X217 & W610X241 \\
\hline \multicolumn{2}{|c|}{$\begin{array}{l}\text { Maximum inter storey } \\
\text { drift ratio }\end{array}$} & 0,96 & 0,95 & 0,97 & 0,93 \\
\hline \multicolumn{2}{|c|}{$\begin{array}{l}\text { Maximum } \quad \text { Strength } \\
\text { Ratio }\end{array}$} & 0,99 & 0,82 & 0,99 & 0,88 \\
\hline \multicolumn{2}{|c|}{ Top storey drift (cm) } & 11,97 & 11,24 & 12,60 & 11,23 \\
\hline \multicolumn{2}{|c|}{ Minimum Weight (kg) } & 42220,050 & 55089,580 & 39478,250 & 46451,310 \\
\hline
\end{tabular}

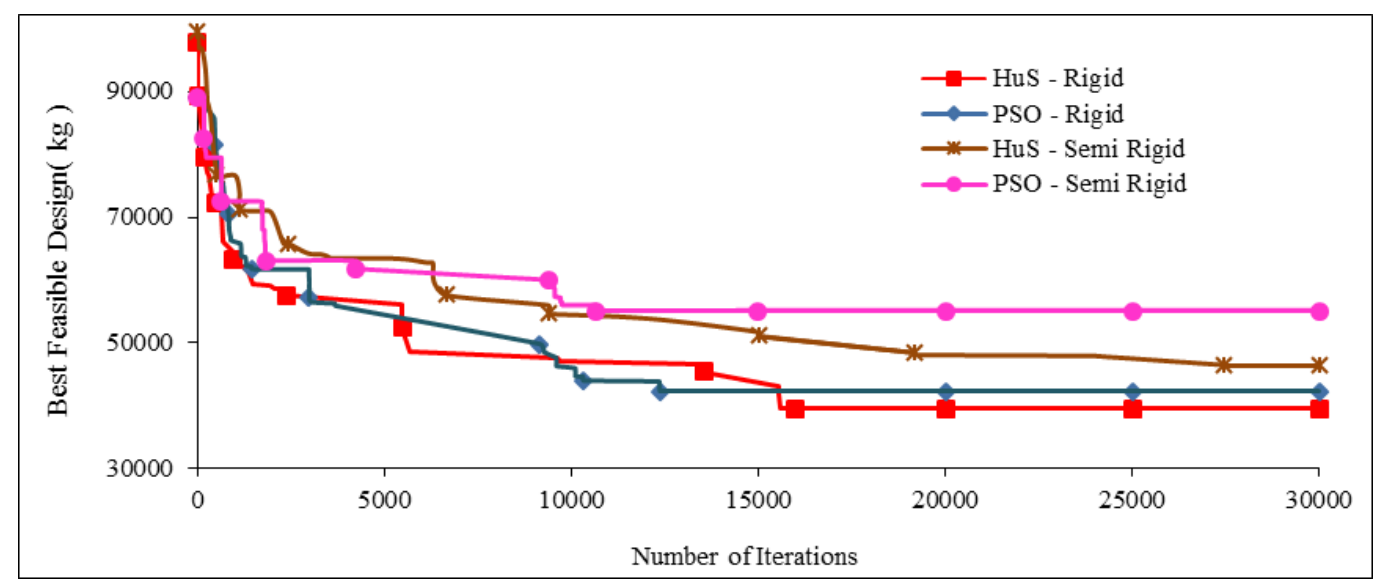

Figure 11. Design History Graph for Twelve-storey, Four-bay Steel Frame

\section{CONCLUSIONS}

In this study, a hunting search optimization based optimum design algorithm is presented for unbraced steel frames with semi-rigid connections. Developed computer program analyzes the nonlinear steel frame with flexible connections, taking into account the LRFD-AISC specifications and selects $\mathrm{W}$ sections from ready section lists available in the literature. Experimental studies in the literature declare that the connection flexibility affects the distribution of forces in the frame and leads to an increase in the drift of whole structure. This makes it necessary to consider P- $\Delta$ effect in the frame analysis. There are several connection models in the literature. Among them end plate without column stiffeners connection model is carried out in the present study. Analysis and design routine is modified in such a way that it includes the flexibility and geometry of end-plate connection. For the determination of the effect of joint flexibility on the behavior of whole structure, 
example problems are also designed as rigid frames. This way, a comparison between both assumptions is carried out and it is noticed that semi-rigid connection assumption results in heavier frames. According to the observations, since great amount of horizontal displacement exist in the flexible connections, displacement constraints become dominant in the design. Therefore, algorithm selects stronger sections to satisfy these constraints. As a result, the weight of the whole structure designed with partially restrained connection assumption becomes greater than the one designed with fully restrained connection assumption. The second part of the study is devoted to the demonstration of the efficiency of presented hunting search-based design algorithm. To do this, the same analysis and design routine is automated with particle swarm optimizer. The same numerical problems are solved by this algorithm, once again. Results show that hunting search produces better designs compared to particle swarm optimizer.

\section{REFERENCES}

[1] Kameshki, E.S. and Saka, M.P., "Optimum Design of Nonlinear Steel Frames with Semi-rigid Connections using a Genetic Algorithm", Computers and Structures, 2001, Vol. 79, pp. 1593-1604.

[2] He, S., Prempain, E. and Wu, Q.H., "An Improved Particle Swarm Optimizer for Mechanical Design Optimization Problems", Engineering Optimization, 2004, Vol. 36, No. 5, pp. 585-605.

[3] Saka, M.P., "Optimum Design of Steel Frames using Stochastic Search Techniques based on Natural Phenomena: A Review", Civil Engineering Computations: Tools and Techniques, Ed. B. H. V. Topping, Saxe-Coburgh Publications, 2007, Chapter 6: pp. 105-147.

[4] Hasançebi, O., Çarbaş, S., Doğan, E., Erdal, F. and Saka, M.P., "Performance Evaluation of Metaheuristic Search Techniques in the Optimum Design of Real Size Pin Jointed Structures", Computers and Structures, 2009, Vol. 87, No. 5-6, pp. 284-302.

[5] Hasançebi, O., Çarbaş, S. and Saka, M.P., "Improving the Performance of Simulated Annealing in Structural Optimization", Journal of Structural and Multidisiplinary Optimization, 2010, Vol. 41, pp: 189-203.

[6] Degertekin, S.O. and Hayalioglu, M.S., "Harmony Search Algorithm for Minimum Cost Design of Steel Frames with Semi-rigid Connections and Column Bases", Journal of Structural and Multidisiplinary Optimization, 2010, Vol. 42, pp. 755-768.

[7] Oftadeh, R., Mahjoob, M.J. and Shariatpanahi, M., "A Novel Meta-heuristic Optimization Algorithm Inspired by Group Hunting of Animals: Hunting Search", Computers Mathematics with Applications, 2010, Vol. 60, pp. 2087-2098.

[8] Doğan, E. and Saka, M.P. "Optimum Design of Steel Frames to LRFD- AISC Using Particle Swarm Optimization”, Advances in Engineering Software, 2012, Vol. 46, No.1, 27-34.

[9] McGuire, W., "Steel Structures", Prentice-Hall, 1968.

[10] Majid, K.I., "Nonlinear Structures", London Butterworth, 1972.

[11] Chen, W.F.,"Practical Analysis for Semi-Rigid Frame Design”, World Scientific Pub Co Inc., 1999.

[12] Chan, S.L. and Chui, P.P.T., "Non-Linear Static and Cyclic Analysis of Steel Frames with Semi-Rigid Connections", Elsevier, 2000.

[13] Faella, C., Piluso, V. and Rizzano, G., "Structural Steel Semirigid Connection"s, CRC Press LLC, Boca Raton, 2000.

[14] Kochenberger, G.A. and Glover, F., "Handbook of Meta-Heuristics", Kluwer Academic Publishers, 2003.

[15] Christensen, P.W., "An Introduction to Structural Optimization”, Springer, Linköping, Sweden, 179-200, 2008. 
[16] Kennedy, J. and Eberhartm, R.C., "Particle Swarm Optimization", Proceedings of IEEE International Conference on Neural Networks, NJ, 1995, Piscataway.

[17] Liu, H., Shichang, S. and Ajith, A., "Particle Swarm approach to Scheduling Work-flow Applications in Distributed Data-intensive Computing Environments", Proceedings of the 6th International Conference on Intelligent Systems Design and Applications, 2006, (ISDA'06) : 0-7695-2528-8/06.

[18] Doğan, E. and Saka, M.P., "Optimum Design of Steel Frames to LRFD- AISC using Particle Swarm Optimization", Proceedings of The 9th International Conference on Computational Structures Technology, 2-5 September, Athens, Greece, 2008.

[19] Doğan, E. and Saka, M.P., "Particle Swarm Optimization Design of Moment Resisting Steel Frames with Semi-rigid Connections to LRFD-AISC", Proceedings of the 8th World Congress on Structural and Multidisciplinary Optimization, 2009.

[20] Hasançebi, O. and Azad, K.S., "A Comparison of Metaheuristics in Structural Optimization" Intl. Conf. on Advances in Civil, Structural and Mechanical Engineering, 2013, CSM 2013, pp. 18-22.

[21] "LRFD-AISC", Manual of Steel Construction - Load and Resistance Factor Design, SA, 1986. 